In seinem Verlag Dorfpresse Gattikon (Zürich) hat B. Hürlimann, gewissermaßen als Hobby-Arbeit, eine Neuausgabe von Gabriel Walsers "Atlas der alten Eidgenossenschaft aus dem Jahre 1769» erscheinen lassen. Für den hervorragend gelungenen Faksimile-Druck, auf hadernhaltigem Büttenpapier mit antiker Rippung, und die Handkolorierung wurden, auf mehrere Jahre verteilt, einige Tausend Freizeitstunden aufgewendet, und dazu traten große Liebe zur Sache und vorzügliches Fachwissen. Der Atlas gliedert sich in zwanzig Kartenblätter im Format 64 x 53,5 cm. Zwei von ihnen widmen sich dem Gebiet der Schweiz als ganzem, die 18 übrigen den 13 alten Orten sowie den «Zugewandten» St.
Gallen (Abtei und Stadt), Graubünden, Wallis und Genf und der Landgrafschaft Thurgau. Schöpfer des Werkes war der Appenzeller Gabriel Walser (1695-1776), Pfarrer zu Speicher und später in der reformierten Gemeinde Berneck (St. Galler Rheintal). Insgesamt verdankt man ihm 21 gedruckte und weitere 9 handgezeichnete Karten; von den letztgenannten hat eine 1766 entstandene Karte des St. Galler Rheintals, die man während langer Zeit als verschollen betrachtete, dank den Bemühungen des Zürcher Geographen A. Dürst, der nachstehend das Kartenwerk Walsers würdigt, vor kurzem wieder aufgefunden werden können.

Sch.

\title{
Die Bedeutung der Karten Gabriel Walsers
}

\section{Arthur Dürst}

Pfarrer Walser war bescheiden genug, die Bedeutung seiner Karten nicht zu überschätzen. Er wußte um die ungelösten Probleme - «denn es ist was schweres, eine accurate Landcharte von einem Land auszufertigen, das so viele hohe Berge und Thäler hat" - und er zeigte selber zahlreiche eigene Fehler auf, wie zum Beispiel: «in der Walliser-Charte ist ein Fehler, welchen ich gern gestehe; denn die Gränzen von Wallis gegen dem Bern-Gebiet gehen viel weiter, als sie in der Charte gezeichnet sind.» Walser glaubte, durch seine Bemühungen zu einer inhaltlich bereicherten und berichtigten Darstellung der Eidgenossenschaft beigetragen zu haben und wußte, $\mathrm{da} ß$ durch Bemühungen anderer seine eigenen Karten bald überholt sein würden: "Wenn auch diese nach und nach verbessert werden, so kann leicht eine allgemeine richtige Schweitzer-Charte zum Vorschein kommen.»

$\mathrm{Da} ß$ der von Walser vorgezeichnete Weg des steten Kompilierens und Korrigierens nicht $\mathrm{zu}$ dem von ihm anvisierten Ziel führen konnte, sondern daß ein Neubeginn auf mathematisch-geometrischer Grundlage nötig war, konnte er schließlich als Theologe kaum wissen.

Die Bedeutung der Walserschen Karten wird von den heutigen Fachleuten meist verkannt, weil sie mit nicht adaequaten Maßstäben messen. Sie stïizen sich auf die zugegebenermaßen primitive Darstellung der Gebirge, auf die Tatsache, daß Walser seine Objekte nicht vermessen, sondern bloß nach
Marschzeitangaben und geschätzten Distanzen in seine Karten eingetragen hat, wodurch natürlich die Lagegenauigkeit der dargestellten Örtlichkeiten sehr zu wünschen übrig läßt. Die vielzitierten Vergleiche mit Gyger und Scheuchzer, deren Schweizer Karten eine bessere Gebirgsdarstellung aufweisen, hinken beträchtlich, da Walser viel größere Maßstäbe verwendet hat als jene. Endlich kennen ja die meisten Beurteiler bloß die gedruckten Karten, in welchen die Originalzeichnungen Walsers durch die Technik der Radiernadel und durch die Interpretation des Stechers übersetzt worden sind. Daß die vergleichsweise naive Darstellungsart vieler Details in den Karten dem Zeitgeschmack entsprach, sei nur am Rande vermerkt.

Viel wichtiger als diese Erwägungen ist jedoch die Tatsache, daß die Zeit Walsers, von einigen Gelehrten abgesehen, keinerlei Interesse an der Bergwelt hatte. Walsers Karten boten einer Bevölkerung, die geographisch weit geringer informiert war als $\mathbf{z}$. B. die heutige, einen durchaus brauchbaren Úberblick über die nähere und fernere Heimat; man verfolgte darin die Geschehnisse der damals überaus beliebten Kalendergeschichten, und man benützte die Karten auch für imaginäre oder wirkliche Reisen in Helvetien. Daß Walser seinen Karten diese letztere Aufgabe ausdrücklich zuwies, sagt er selbst an vielen Stellen, wie zum Beispiel beim Gotthardpaß: "Weil dieses die merkwürdigste Landstraße aus der Schweitz in Jtalien ist, und von vielen tausend Per- 
sonen zu Pferd und Fuß bewandert wird, so wird es den Reisenden eine Gefälligkeit seyn, wenn ich mich hier zu einem Wegweiser darstelle, und ihnen zugleich eine accurate Marsch-Route in meiner Landcharte, ... . liefere.» Dabei wurde die Geländedarstellung vernachläßigt, und manch ein Berg mußte eines eingefügten Textes wegen, der auf irgend eine Besonderheit hinwies, Platz machen.

Gegenüber der vierblättrigen Schweizer Karte von Scheuchzer (1712), die bis zum Erscheinen der Walser-Karten die populärste Darstellung unseres Landes war, bedeuteten diese immerhin in mancher Hinsicht einen gewissen Fortschritt. Einmal hatte jeder Kanton seine eigene Karte, und für einige von ihnen war es entweder die erste gedruckte Karte (Solothurn) oder die allererste überhaupt (Uri, Zug). Dann zeigten die Walserschen Karten immerhin einiges mehr an Örtlichkeiten und Objekten; sie waren zudem sehr übersichtlich, an manchen Stellen korrigiert, und differenzierten in den Legenden weitergehend, wie dies die Bündner Karte, als die inhaltsreichste, mit 17 Signaturen eindrücklich demonstriert. Außerdem sei nicht vergessen, daß die Eidgenossenschaft durch Walsers Atlas, nach Johannes Stumpfs "Landtaflen» von 1552, also nach über zweihundert Jahren, ihren zweiten Landesatlas erhielt.

\section{Ehrungen - Distinctions}

Die "Gesellschaft für Erdkunde» zu Berlin hat Prof. Dr. Eduard Imhof in Erlenbach/Zürich aus Anlaß seines 75 . Geburtstages und «in Würdigung seiner hervorragenden Verdienste um die kartographische Wissenschaft» die Goldene Alexander-vonHumboldt-Medaille verliehen.

\section{Ernennungen - Nominations}

Der Bundesrat hat Dr. Fritz Müller, von Steinmaur $\mathrm{ZH}$, geb. 1926, bis dahin Professor für Glaziologie an der McGill-Universität in Montreal (Kanada), als ordentlichen Professor für Geographie an der Eidg. Technischen Hochschule in Zürich gewählt.

Ferner ist Dr. Ernst Winkler, von Wangen $\mathrm{ZH}$, geb. 1907, zurzeit außerordentlicher Professor für Landesplanung und Kulturgeographie an der ETH
Die Popularität der Walser-Karten, "von den Bilder-Krämern aller Orten zu haben», war groß, und die Homännischen Erben hatten sich wahrlich nicht über mangelnden Absatz zu beklagen. Leider ist es nicht möglich, die Auflagenhöhe der einzelnen Karten auch nur annähernd zu errechnen, doch muß sie, gemessen an der Tatsache, daß Einzelblätter des Atlasses noch heute in den Antiquariaten recht häufig sind, sehr hoch gewesen sein.

So läßt sich abschließend doch feststellen, daß die Karten Walsers durch ihre Popularität und enorm weite Verbreitung im Inland das Bild der Heimat besonders bei der einfachen Bevölkerung prägten und vertieften und durch die ebenfalls große Beliebtheit im Ausland nicht wenig Reklame für den eben zaghaft beginnenden Tourismus in unserem Lande machten. Da der Verlag der Homännischen Erben um die Mitte des Jahrhunderts Niederlassungen in Augsburg, Breslau, Frankfurt, Leipzig, Straßburg, St. Petersburg, Stockholm, Ulm, London und Paris unterhielt, wo der Schweizer Atlas als Ganzes und alle Kantonskarten einzeln zu haben waren, ist gerade diese Werbewirkung für unser Land nicht gering $\mathrm{zu}$ achten. Hierin und im vorgenannten weniger im kartenhistorischen Bereich - liegt die große Bedeutung der Karten Pfarrer Gabriel Walsers.

Prof. Imhof ist ferner von der Schweizerischen Gesellschaft für Kartographie «in Anerkennung seiner überragenden Verdienste um die schweizerische Kartographie und deren Ansehen im Auslande, sowie seiner Förderung der internationalen Zusammenarbeit" zum Ehrenmitglied ernannt worden. Wir gratulieren herzlich.

Die Redaktion
Zürich, zum Ordinarius ad personam für das gleiche Lehrgebiet ernannt worden.

Der Regierungsrat des Kantons Bern hat Dr. Max Schüepp in Zürich zum außerordentlichen Professor für Meteorologie an der Universität Bern ernannt.

Unsere herzliche Gratulation! Die Redaktion 